Research paper

\title{
ArgO145, a Stx2a prophage of a bovine O145:H- STEC strain, is closely related to phages of virulent human strains
}

\author{
Krüger A. ${ }^{\text {a,*, }}$, Burgán J. ${ }^{\text {a }}$, Friedrich A.W. ${ }^{\mathrm{b}}$, Rossen J.W.A. ${ }^{\mathrm{b}}$, Lucchesi P.M.A. ${ }^{\mathrm{a}}$

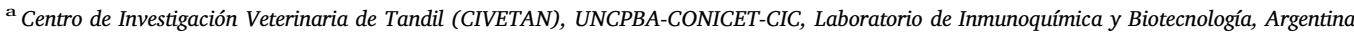 \\ ${ }^{\mathrm{b}}$ University of Groningen, University Medical Center Groningen, Department of Medical Microbiology, The Netherlands.
}

\section{A R T I C L E I N F O}

\section{Keywords:}

Stx-converting phages

Shiga toxin-producing Escherichia coli

O145:H-

\begin{abstract}
A B S T R A C T
Shiga toxins (Stx) are the main virulence factor of a pathogroup of Escherichia coli strains that cause severe human diseases. These toxins are encoded in prophages (Stx prophages), and generally their expression depends on prophage induction. Several studies have reported high diversity among both Stx prophages and Stx. In particular, the toxin subtype Stx2a is associated with high virulence and HUS. Here, we report the genome of ArgO145, an inducible Stx2a prophage identified in a bovine O145:H- strain which produced high levels of Shiga toxin and Stx phage particles. The ArgO145 genome shared lambda phage organization, with recombination, regulation, replication, lysis, and head and tail structural gene regions, although some lambda genes encoding regulatory proteins could not be identified. Remarkably, some Stx2a phages of strains isolated from patients in other countries showed high similarity to ArgO145.
\end{abstract}

\section{Introduction}

Phages (virus that infect bacteria) represent the most abundant biological entities on earth (Hatfull and Hendrix, 2011; Suttle, 2016). They are found in very large numbers wherever their host live (Kutter and Sulakvelidze, 2004), and it is estimated that they outnumber bacteria by 10 -fold (Hatfull and Hendrix, 2011). Phages play key roles in regulating the microbial balance in ecosystems, as phage lytic activity affects bacterial mortality and non-lytic activity may affect bacterial traits. Moreover, some phages play important roles in bacterial virulence, converting the host from a nonpathogenic strain to a virulent strain (Kutter and Sulakvelidze, 2004).

The phage-encoded Shiga toxin (Stx) is the main virulence factor of a pathogroup of Escherichia coli strains that cause severe human diseases, such as hemorrhagic colitis and hemolytic-uremic syndrome (HUS) (Karmali et al., 1985; Riley et al., 1983). These strains, named STEC (Shiga toxin producing E. coli) or VTEC (verocytotoxigenic E. coli) can carry one or more Shiga toxin-encoding genes $(s t x)$ in their genome. Generally, the $s t x$ genes are located within the phage lysis region, and expression of $s t x$ depends primarily on prophage induction (Wagner and Waldor, 2002; Waldor and Friedman, 2005). Several studies have shown that there is diversity in both Shiga toxin and Stx phage families. Furthermore, epidemiological data suggest associations between specific Stx subtypes and severity of human illness, being Stx2a the subtype most associated with high virulence and HUS (Chui et al., 2015; Friedrich et al., 2002; Persson et al., 2007). However, little is known about characteristics of Stx phages that may contribute to high virulence. Of particular interest is the genetic region upstream of the stx genes that could regulate stx expression. Interestingly, some different anti-terminator $\mathrm{Q}$ sequences have been reported, and there are studies that showed a relationship between $\mathrm{Q}$ allele and level of stx expression (Ahmad and Zurek, 2006; Lejeune et al., 2004; Steyert et al., 2012).

Surveillance data on STEC infections indicates that approximately half of HUS confirmed cases are associated with serogroup 0157, and that $026,091,0103,0111,0121$ and 0145 serogroups are the most frequently ones isolated from non-O157 cases (EFSA Panel, 2013; Gould et al., 2013). Particularly, O145 strains have been commonly isolated in several countries, like U.S., Canada, Germany, U.K., Spain, Italy, Denmark, Finland, Japan (FSIS, 2011), and have been associated with outbreaks in Japan, U.S., Belgium, Norway (De Schrijver et al., 2008; Kaspar et al., 2010; Taylor et al., 2013; Wahl et al., 2011). In Argentina, STEC 0145:H- was firstly detected in cattle in 2001 (Padola et al., 2002). Strains belonging to this serotype were later associated with one family and one kindergarten outbreak (Rivas et al., 2010). Currently, $\mathrm{O} 145: \mathrm{H}$ - is the serotype that follows $\mathrm{O} 157: \mathrm{H7}$ in prevalence in this country (Zotta et al., 2014).

Taking into account that cattle is the main reservoir of most STEC strains (Gyles, 2007; Persad and LeJeune, 2014), and that, to our

\footnotetext{
* Corresponding author at: Laboratorio de Inmunoquímica y Biotecnología, Centro de Investigación Veterinaria de Tandil (CIVETAN), Facultad de Ciencias Veterinarias, UNCPBA, Campus Universitario, Arroyo Seco s/n, B7000 Tandil, Buenos Aires, Argentina.

E-mail address: akruger@vet.unicen.edu.ar (A. Krüger).
} 
knowledge, there are few studies analyzing DNA sequences of Stx phages from bovine strains (Beutin et al., 2013; Johansen et al., 2001), the aims of this study were to characterize and determine the whole genome sequence of a Stx2a prophage present in an STEC strain representing one of the first described $s t x_{2}$-positive $0145: \mathrm{H}$ - strains isolated from cattle in Argentina, and to perform a comparative analysis against complete Stx phage sequences available in databases.

\section{Materials and methods}

\subsection{Bacterial strains}

FB5, a STEC strain producing high cytotoxicity titers on Vero cells (Krüger et al., 2011) was chosen for a deep characterization of a Stx2 phage from bovine origin. This strain had been isolated from a feedlot cow during a rectal swab screening for STEC detection in 2001-2002, and reported among the first isolates of STEC 0145:H- in Argentina (Padola et al., 2002). Further characterization showed that strain FB5 is positive for $s t x_{2 a}$, eae $\gamma$ and $e h x A$ genes (Krüger et al., 2011).

$E$. coli laboratory strain DH5 $\alpha$ was used as an indicator strain for phage quantification in double-agar-layer plaque assays and $E$. coli EDL933 strain as a positive control for phage and toxin production. Nine $E$. coli strains were selected for studies on phage infectivity and lysogenization: DH5a, HB101 and Y1090 E. coli K-12 derivatives; two ETEC strains, one O157 and one O145 EPEC strain, one O157 and one O145 STEC (stx $x_{1}$-positive, stx $x_{2}$-negative) strain.

\subsection{Evaluation of Shiga toxin and phage production in strain FB5}

Shiga toxin and phage production were evaluated in strain FB5 using an inducing agent (mitomycin $\mathrm{C}$ ) and under non-inducing conditions. The EDL933 strain was also included as a positive control of Stx phage induction. Aliquots of overnight cultures in Luria Bertani (LB) broth were inoculated onto fresh LB medium and incubated at $37^{\circ} \mathrm{C}$ and $180 \mathrm{rpm}$ up to an optical density at $600 \mathrm{~nm}\left(\mathrm{OD}_{600}\right) \approx 0.2-0.3$, after which each culture was subdivided into two flasks. Mitomycin C (final concentration $0.5 \mu \mathrm{g} / \mathrm{ml}$ ) was added to one of the subcultures and the incubation was continued under the same conditions.

\subsubsection{Analysis of stx $_{2 a}$ expression}

The expression of $s t x_{2}$ was evaluated 90 min after mitomycin C addition. Total RNA was purified from $500 \mu$ l aliquots (SV total RNA isolation system; Promega) and treated with DNase I (Roche Diagnostics $\mathrm{GmbH}$ ) at $37^{\circ} \mathrm{C}$ for $1 \mathrm{~h}$. cDNA was synthesized from $1 \mu \mathrm{g}$ total RNA with the High Capacity cDNA Reverse Transcription Kit (Applied Biosystems) and diluted 1/10 for qPCR reactions. Two qPCRs were carried out for each sample on a OneStep Plus Real-Time PCR System (Applied Biosystems). Primers 2SF and 2R (de Sablet et al., 2008) were used to amplify the $s t x_{2 a}$ gene, and TufAqR plus TufAqF for the tufA gene (de Sablet et al., 2008). Each reaction was performed in a $20 \mu \mathrm{l}$ reaction mix containing $10 \mu \mathrm{l} 2 \times$ SYBR Green mix (FastStart Universal SYBR Green Master, Roche) and either primers 2SF and 2R at $400 \mathrm{nM}$ each, or TufAqR and TufAqF at $300 \mathrm{nM}$ each. Expression levels of $s t x_{2 a}$ were normalized against tufA.

In order to evaluate extracellular Stx2a production, supernatants from cultures at $18 \mathrm{~h}$ were obtained by centrifugation at $12,000 \times g$ for 10 min, diluted $1 / 10$ in LB and analyzed with an enzyme immunoassay (EIA, Ridascreen Verotoxin, R-Biopharm) according to the manufacturer instructions.

\subsubsection{Quantitative analysis of phage production}

Phages were purified from cultures at $3 \mathrm{~h}$ post induction. Briefly, a $2.6 \mathrm{ml}$ aliquot of each culture was centrifuged at $10,000 \times g$ at $4{ }^{\circ} \mathrm{C}$ for $10 \mathrm{~min}$. Supernatants were centrifuged again in the same conditions and filtered through low-protein-binding $0.22 \mu \mathrm{m}$ membrane filters (Millex-GP, Millipore).
The number of infective phage particles was determined by the double-agar-layer method. For this purpose, filtrates and corresponding tenfold serial dilutions were mixed with $500 \mu \mathrm{l}$ of an exponential phase culture of $E$. coli $\mathrm{DH} 5 \alpha\left(\mathrm{OD}_{600}=0.6-0.8\right)$ and incubated for $30 \mathrm{~min}$ at $37^{\circ} \mathrm{C}$ with shaking $(120 \mathrm{rpm})$. This suspension was then mixed with $3 \mathrm{ml}$ of LB soft agar $(0.75 \% \mathrm{w} / \mathrm{v})$ supplemented with $9 \mathrm{mM} \mathrm{CaCl}_{2}$ and poured onto LB agar plates. After $18 \mathrm{~h}$ incubation, visible lysis plaques were enumerated and phage titers were expressed as plaque forming units $(\mathrm{pfu}) / \mathrm{ml}$.

For quantitative PCR analysis of Stx2 phage particles, filtrates were treated with chloroform $(1 / 10)$, vortexed and centrifuged at $10,000 \times g$ for $5 \mathrm{~min}$. Phage particles were concentrated 5 times by centrifugation of those supernatants at $35,000 \times g$ for $30 \mathrm{~min}$ at $4{ }^{\circ} \mathrm{C}$. To degrade any remaining bacterial DNA, phage suspensions were treated with DNase I (Roche Diagnostics $\mathrm{GmbH}$ ) at $37^{\circ} \mathrm{C}$ for $1 \mathrm{~h}$. Phage DNA was purified with a commercial kit (High Pure Viral Nucleic Acid Kit, Roche) and diluted $1 / 100$ for $\mathrm{qPCR}$ reactions. Amplification and detection were performed on a OneStep Plus Real-Time PCR System (Applied Biosystems) with primers $2 \mathrm{SF}$ and $2 \mathrm{R}$ as described before. It was assumed that one copy of the stx gene corresponds to one Stx phage particle.

\subsubsection{Evaluation of Stx2a phage infectivity and generation of lysogens in $E$. coli strains}

Filtered phage suspensions of induced strain FB5 cultures were assayed onto the nine selected $E$. coli strains mentioned above. Briefly, each $E$. coli strain was grown in $5 \mathrm{ml} \mathrm{LB}$ broth at $37^{\circ} \mathrm{C}$ and $180 \mathrm{rpm}$. Five hundred microliter of exponential-phase cultures were mixed with $2 \mathrm{ml} \mathrm{LB}$ soft agar $(0.75 \% \mathrm{w} / \mathrm{v})$ containing $9 \mathrm{mM} \mathrm{CaCl}_{2}$ and poured onto a LB agar plate. A drop of the phage suspension and $1 / 10$ dilutions were spotted onto each host monolayer and incubated at $37^{\circ} \mathrm{C}$ overnight.

Small portions of drop area (with or without visible lysis) were picked and streaked onto an agar plate by a sterile inoculation loop. After overnight incubation at $37^{\circ} \mathrm{C}$ for $18 \mathrm{~h}$, a loop of confluent bacterial growth zone and 20-30 single colonies were suspended in sterile water and screened by PCR for $s t x_{2}$. Three $s t x_{2}$-positive colonies from each host were subcultivated three times on LB agar plates. One stable lysogen was tested for its ability to produce infective phages. For this purpose, one single lysogenized colony was cultured in LB medium at $37^{\circ} \mathrm{C}$ and $120 \mathrm{rpm} 18 \mathrm{~h}$. Overnight cultures were inoculated in fresh LB and treated as described above for viable phage counting. Additionally, lysis plaques were PCR screened for $s t x_{2}$. Stx2a production was tested in overnight supernatants of mitomycin C-induced cultures.

\subsection{Genomic DNA extraction and sequencing}

Bacterial DNA was extracted from an overnight culture of strain FB5 with the Ultraclean Microbial DNA isolation kit (MoBio). The DNA concentration and purity were measured using a NanoDrop 2000c spectrophotometer (Thermo Fisher Scientific) and the Qubit doublestranded DNA (dsDNA) HS and BR assay kits (Life Technologies). One nanogram of bacterial DNA was used for library preparation. The DNA library was prepared using the Nextera XT library preparation kit with the Nextera XT v2 index kit (Illumina). Subsequently, the library was sequenced on a MiSeq sequencer, using the MiSeq reagent kit v2 generating 250-bp paired-end reads (Illumina). Sequencing was aimed at a coverage of at least 60 -fold. MiSeq data were processed with MiSeq control software v2.4.0.4 and MiSeq Reporter v2.4 (Illumina). Quality trimming of reads was performed with CLC Genomics Workbench 7.0.4 (Qiagen) using a minimum Phred (Q) score of 28 (Kluytmans-Van Den Bergh et al., 2016). In addition, a mate-pair DNA library was prepared using the Mate Pair Library Prep Kit v2 (Illumina) according to the manufacturer's instructions followed by running on the Miseq for generating 100 -bp reads. 


\subsection{Bacterial genome assembly and phage genome detection}

Reads from mate pair sequencing were combined with those from paired-end sequencing and were de novo assembled using CLC Genomics Workbench. The genome of STEC strain FB5 was analyzed with BLASTN (https://blast.ncbi.nlm.nih.gov/) using the $s t x_{2 a}$ sequence from the phage 933W (AF125520) as query sequence to identify contigs of interest and with PHAge Search Tool Enhanced Release (PHASTER) web server (http://phaster.ca) to identify prophage genomes (Arndt et al., 2016).

\subsection{Genome annotation and comparative analyses}

The sequence of the identified $s t x_{2 a}$-encoding prophage, named ArgO145, was analyzed with Open Reading Frame (ORF) Finder (https://www.ncbi.nlm.nih.gov/orffinder) to search for potential protein encoding segments using the following settings: minimal ORF length of $150 \mathrm{bp}$, a standard genetic code and "ATG" and alternative initiation codons. Results from ORF finder were combined with the coding sequences detected by PHASTER. The translated amino acid sequences were examined with SMART BLAST (https://blast.ncbi.nlm. nih.gov/smartblast/?LINK_LOC = BlastHomeLink) to search and identify putative proteins.

BLAST (https://blast.ncbi.nlm.nih.gov/Blast.cgi) was used to compare selected ORFs and the complete predicted genome of the ArgO145 against sequences in the database. Prophage genomes showing the best matches to ArgO145 were further aligned and visualized with Easyfig 2.2.2 (Sullivan et al., 2011). In addition, the prophage genome of ArgO145 was compared with selected prophages of 0157 and nonO157 STEC strains using BRIG (BLAST Ring Image Generator).

\subsection{Accession number}

The complete nucleotide sequence of the prophage ArgO145 was deposited in GenBank under accession number KY914478.

\section{Results}

Strain FB5, one of the first isolates of STEC 0145 in Argentina, was selected to study a Stx phage of a bovine strain. Comparative qPCR analysis showed that $s t x_{2 a}$ expression levels in strain FB5 cultured in untreated conditions are similar to those observed in E. coli EDL933 reference strain. In addition, in both strains the treatment with mitomycin C incremented the $s t x_{2 a}$ mRNA levels approximately 100 -fold (Fig. 1 A). High extracellular Stx production was confirmed by enzyme immunoassay, as results from strain FB5 overnight supernatants were classified strongly positive $(+4)$ according to the kit classification.

The ability of strain FB5 to produce Stx2a phages was also assessed for mitomycin $\mathrm{C}$ treated and untreated cultures. By double-agar-layer method, titers of $810^{3}$ and $910^{6} \mathrm{pfu} / \mathrm{ml}$ were observed for supernatants of untreated und treated cultures, respectively. Lysis plaques were assayed by hybridization, which revealed that all plaques belonged to Stx2 phages. Mitomycin C induction was also evidenced by qPCR results that indicated two order of magnitude higher levels of Stx2a phage particles in treated cultures relative to the levels seen with spontaneous induction (Fig. 1 B). In agreement with the results of Stx toxin production, strain FB5 produced Stx2a phage levels similar than those of EDL933.

Infectivity of Stx phages induced from strain FB5 was tested on agar monolayers containing diverse selected E. coli strains. Drops of undiluted and 1/10 diluted strain FB5 filtrates produced confluent lysis and/or individual plaques on K-12 derivative E. coli strains (Fig. 1 C). Presence of Stx 2 phages in drop areas were confirmed by PCR. The spot test was negative for the remaining $E$. coli strains.

Production of $s t x_{2}$ lysogens was successful with each of the three K12 derivative strains tested. However, $s t x_{2}$ lysogens were more
A

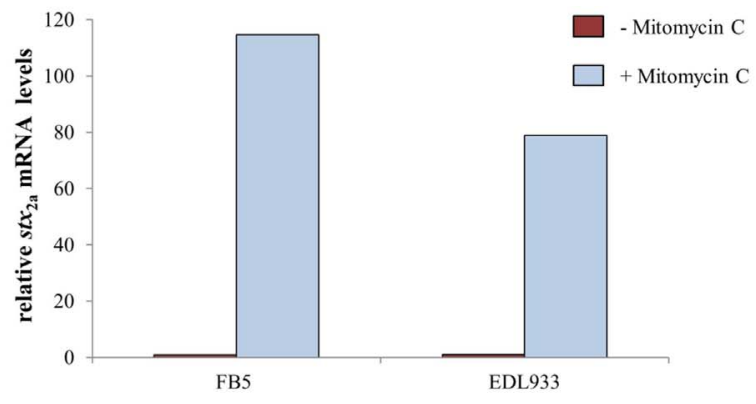

B

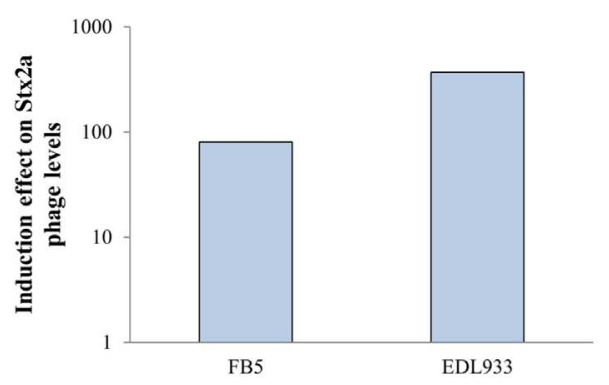

C

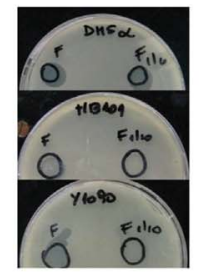

D

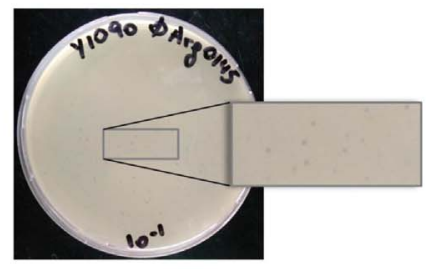

Fig. 1. A) $s t x_{2 a}$ expression by qPCR. Levels of $s t x_{2 a}$ mRNA were normalized against tufA and expressed relative to $s t x_{2 a}$ mRNA levels of untreated EDL933. B) The effect of mitomycin $\mathrm{C}$ on phage production was measured by qPCR. y axis, logarithmic scale of relative increase calculated as the ratio of $s t x_{2 a}$ gene copies in supernatants of cultures treated with mitomycin $\mathrm{C}(0.5 \mu \mathrm{g} / \mathrm{ml})$ to those in supernatants of untreated cultures. C) Infection and lytic effect of ArgO145 phage on DH5 $\alpha$, Y1090 and HB101 E. coli strains. F and F1/10 correspond to drops of undiluted and 1/10 diluted filtered phage suspensions of strain FB5 culture, respectively. D) ArgO145 plaques formed on double layer agar plates with DH5 $\alpha$ as host strain. The image corresponds to quantification of ArgO145 present in $100 \mu \mathrm{l}$ tenfold diluted supernatant of an untreated Y1090 lysogen culture.

frequently detected and showed to be more stable using Y1090 as recipient strain. One stable Y1090 stx $x_{2}$ lysogen was evaluated for phage and toxin production. Infective Stx phages were detected in both treated and untreated cultures (Fig. 1 D), and titers were in the same order of magnitude that those observed in the strain FB5 cultures. In addition, high extracellular Stx production was detected in supernatants of an overnight culture of mitomycin C treated Y1090 stx $x_{2}$ lysogen (classified +4 , strongly positive according to the kit classification).

The whole genome of STEC strain FB5 was sequenced and contigs were analyzed to identify the Stx2a encoding prophage. Only one $s t x_{2}$ copy was detected in strain FB5 genome. A first analysis using data from the de novo assembly of paired-end reads did not allow detection of a complete Stx prophage genome within a single contig (data not shown). However, this was solved by combining data from two sequencing runs, i.e., data obtained from sequencing a paired-end and a mate-paired library. A predicted prophage carrying $s t x_{2 a}$ was identified in a $279 \mathrm{kbp}$ contig. This prophage was named ArgO145. In addition to ArgO145, other 13 non-Stx prophage regions were identified in strain FB5 genome by analysis with PHASTER (3 regions classified as intact phages, 7 incomplete and 3 questionable according to the completeness score). 
Table 1

Main genomic features of ArgO145 prophage.

\begin{tabular}{|c|c|c|c|}
\hline Strand & Start & Stop & Predicted function \\
\hline & 1 & 25 & attL site \\
\hline+ & 220 & 1,389 & Integrase \\
\hline- & 1,555 & 1,373 & DNA-binding protein ${ }^{a}$ \\
\hline- & 2,845 & 2,219 & Adenine methylase \\
\hline+ & 4,382 & 4,588 & Toxin-antitoxin system, antitoxin component \\
\hline+ & 4,594 & 4,893 & Toxin-antitoxin system, toxin component \\
\hline- & 5,804 & 5,439 & HNH endonuclease \\
\hline- & 6,024 & 5,806 & Sugar acetyltransferase inhibitor \\
\hline- & 10,004 & 9,126 & $\mathrm{NinC}$ \\
\hline- & 13,216 & 12,527 & Exonuclease \\
\hline- & 14,163 & 13,213 & RecT \\
\hline- & 14,989 & 14,777 & Kil \\
\hline- & 15,707 & 15,060 & Phage regulatory protein, Rha family \\
\hline- & 17,522 & 16,568 & Type II restriction enzyme BsuBI ${ }^{\mathrm{b}}$ \\
\hline- & 18,988 & 17,519 & Modification methylase BsuBI \\
\hline- & 19,796 & 19,083 & Repressor CI \\
\hline+ & 19,892 & 20,095 & Regulatory protein Cro \\
\hline+ & 20,998 & 22,518 & Helicase \\
\hline+ & 22,508 & 23,479 & DNA primase \\
\hline+ & 23,936 & 24,499 & $\mathrm{NinG}$ \\
\hline+ & 24,496 & 24,690 & $\mathrm{NinH}$ \\
\hline+ & 24,683 & 25,117 & Antiterminator Q \\
\hline+ & 25,366 & 25,518 & DNA methylase \\
\hline+ & 25,559 & 25,634 & tRNA Met-CAT \\
\hline+ & 25,644 & 25,720 & tRNA Arg-TCG \\
\hline+ & 25,734 & 25,810 & tRNA Arg-TCT \\
\hline+ & 25,901 & 26,860 & Shiga-like toxin II subunit A \\
\hline+ & 26,872 & 27,141 & Shiga-like toxin II subunit B \\
\hline+ & 27,627 & 29,564 & Esterase \\
\hline+ & 30,242 & 30,457 & Holin \\
\hline+ & 30,462 & 30,995 & Lysozyme \\
\hline+ & 31,270 & 31,839 & Antirepressor \\
\hline+ & 31,996 & 32,460 & $\mathrm{Rz}$ \\
\hline- & 32,785 & 32,492 & Bor \\
\hline+ & 33,194 & 34,000 & Small subunit terminase \\
\hline+ & 33,981 & 35,687 & Large subunit terminase \\
\hline+ & 35,687 & 37,831 & Portal protein \\
\hline+ & 39,020 & 40,234 & Major capsid protein \\
\hline+ & 42,408 & 44,321 & Tail fiber protein \\
\hline+ & 44,323 & 44,592 & Tail fiber protein \\
\hline+ & 46,835 & 48,103 & Tail fiber protein \\
\hline+ & 48,118 & 48,396 & Outer membrane protein \\
\hline+ & 49,110 & 49,844 & Outer membrane protein Lom precursor \\
\hline \multirow[t]{2}{*}{+} & 51,884 & 52,135 & Bacteriocin \\
\hline & 61,996 & 62,020 & attR site \\
\hline
\end{tabular}

a The predicted protein shows a good alignment (56/60 aa) with the excisionase of the Stx2 converting phage vB_EcoP_24B (ADN68389.1).

b This region shows high nucleotide identity (954/955) with those from PA2, PA8, Stx2a_F765 and VT2phi272. However, an additional C results in a frameshift and in-frame stops in the coding sequence.

Analysis of the genome of the ArgO145 prophage from attL to attR showed a 62,020 bp sequence with a GC content of 50.0\%. Examination of the chromosomal flanking sequences revealed that ArgO145 lies within the tRNA-Arg-CCT gene ( $\operatorname{argW})$, which appears to remain intact. Sequence analysis predicted 83 genes. Forty-three of the gene predicted products showed high identity to annotated proteins and tRNAs reported in other phages. Putative products are listed in Table 1.

At first glance, the ArgO145 genome structure seems to follow the lambda phage organization. In the genome, ORFs for predicted repressor protein $\mathrm{CI}$, regulatory protein Cro, antiterminator Q, and lysis, head and tail gene regions were detected. However, other lambda-like genes encoding regulatory proteins could not be identified.

Like in most Stx phages, the $s t x$ gene was detected downstream $Q$. Directly downstream the stx gene, ArgO145 encodes a predicted $645 \mathrm{bp}$ esterase with a $99 \%$ identical translated sequence to that of the $933 \mathrm{~W}$ bacteriophage (designed locus 933Wp42), that could facilitate STEC colonization and maintenance in the gut (Nübling et al., 2014).

ArgO145 also carries several genes probably associated with phage persistence in the host, some of them useful to circumvent host defense mechanisms. In addition, a toxin-antitoxin system, and three predicted DNA methyltransferases were identified in this prophage. Particularly, it carried genes encoding a Type II restriction-modification BsuBI/PstI system, with a $99 \%$ identity with a previously reported methyltransferase encoded by a Stx phage of a HUS-linked E. coli O104:H4 (Fang et al., 2012).

Whole genome comparison of ArgO145 against sequence databases revealed matches with several Stx phages. Comparative analyses of these phage genomes showed that the best matches (95\% sequence coverage with $99 \%$ of identity) corresponded to phages PA2, PA8, Stx2a_F765 and VT2phi272 (phage accession numbers KP682371, KP682374, AP012534.1 and HQ424691.1, respectively), which were detected in O157:H7 strains isolated from humans (Ogura et al., 2015; Yin et al., 2015; Zhang et al., 2007). Fig. 2 shows sequence alignments of ArgO145 with these Stx2a phages. The sequence of ArgO145 appeared to be shorter than the four mentioned phages. Main differences were related to the absence of the IS629 insertion element in ArgO145 and to the sequence between 4.6 and $7.8 \mathrm{kbp}$ in ArgO145. In this region, ArgO145 encodes a putative toxin, a putative endonuclease and some hypothetical proteins not found in the other four phages, but lacks some genes present in the others.

ArgO145 was also aligned with a selection of Stx2a prophages present in 0157 and non-O157 strains. The comparison revealed a similar gene organization with differences concentrated mostly in the early transcribed region (Fig. 3). Interestingly, regions encoding the integrase and NinC were highly similar to those of the RM13514 phage from an O145:H28 isolate (Cooper et al., 2014) (Fig. 3 B). Alignment of the $s t x$ and flanking genes revealed sequence conservation among the analyzed phages with the highest similarity in the $s t x_{2 a}$ sequences, which encode the same amino acid sequences. ArgO145 differed in the region located at $\sim 45 \mathrm{kbp}$ encoding tail fiber proteins with that of phage P13374 from strain CB13374 and that of the Stx phage from 2011C-3493, both O104:H4 enteroaggregative hemorrhagic E. coli (EAHEC) strains isolated during the German outbreak in 2011 (Ahmed et al., 2012; Beutin et al., 2012) (Fig. 3 B). But in fact, this region was similar among ArgO145 and the phages carried by the other two non0157 strains. The predicted sequence for a tail fiber protein (encoded in the region between $42,408-44,321 \mathrm{bp}$ ) showed $96 \%$ identity with that of the Stx2a prophage from the clinical O145:H28 isolate RM13514 and also a high identity (ranging from 98 to $93 \%$ ) with those reported for short tailed Stx phages recognizing the adsorption target BamA (Smith et al., 2007).

\section{Discussion}

The Stx phages encode and regulate Shiga toxin production, which is considered the main virulence factor of STEC strains (Tyler et al., 2013; Wagner et al., 2001). The family of Stx phages is a heterogeneous group, whose differences in relation to Shiga toxin production and to other phage characteristics that contribute to STEC virulence are poorly understood.

Genetic and phylogenetic analyses of STEC strains propose that some strains isolated from bovines and food have the potential to cause severe illness (Feng et al., 2017; Feng et al., 2014; Krüger et al., 2015). In agreement with these observations, previous studies in our laboratory suggest that Stx phages from some bovine strains are able to be induced to similar levels than those from clinical isolates (Krüger et al., 2011; Lenzi et al., 2016). To contribute to the understanding of the role of Stx phages in HUS epidemiology, we performed a deep characterization of a Stx2a phage carried by an 0145 STEC isolated from cattle. This phage, the only Stx phage carried by strain FB5 according to genome sequencing, was named ArgO145. Evaluations on phage production and phage infectivity confirmed that ArgO145 is an inducible phage able to produce lytic and lysogenic infection.

Genome characterization and nucleotide sequence comparison of 


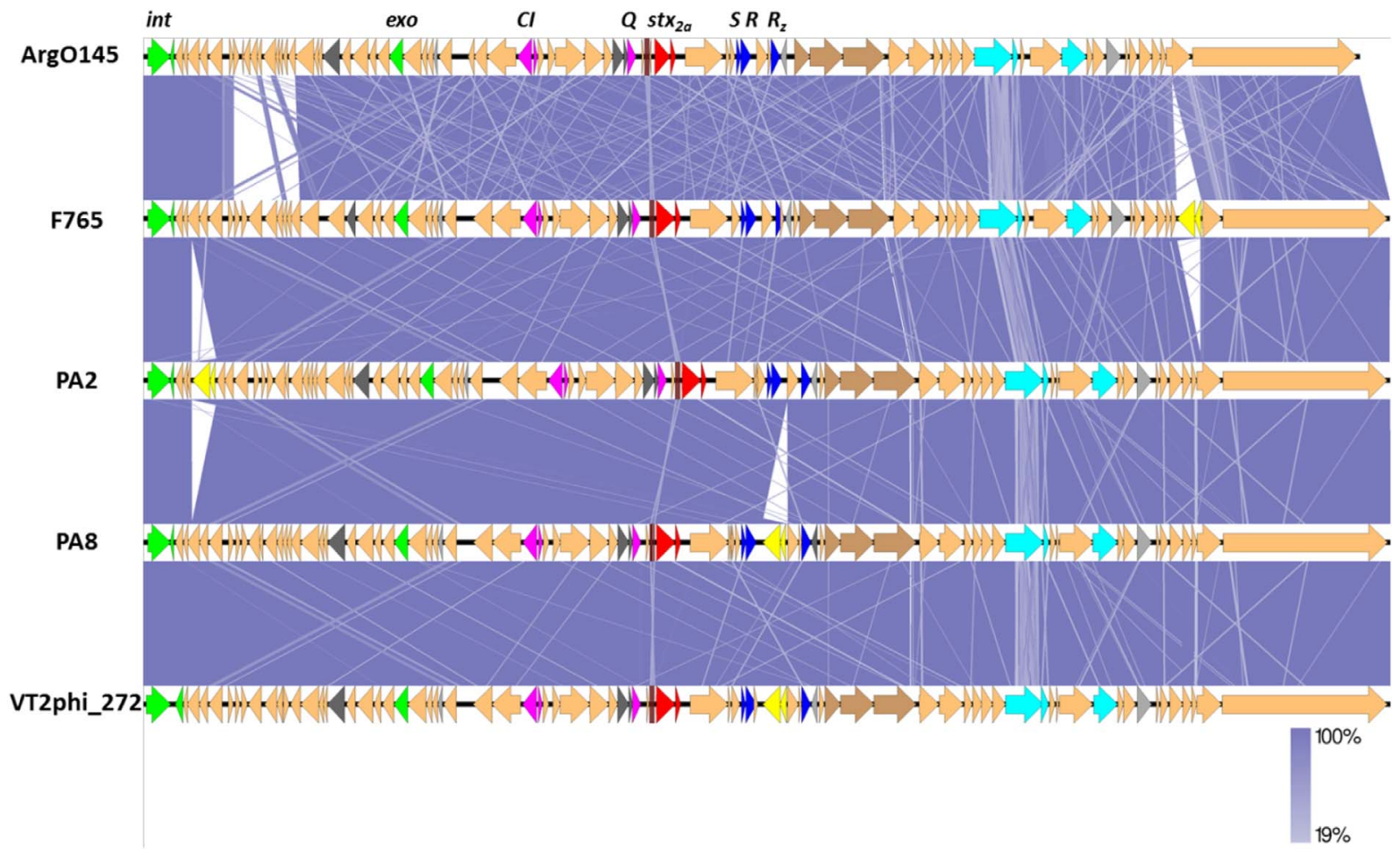

Fig. 2. Whole genome alignments of ArgO145 and four closely related Stx2a prophages.

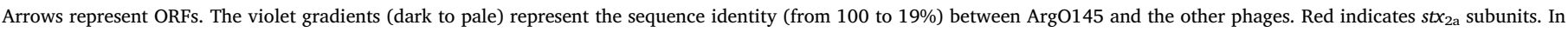

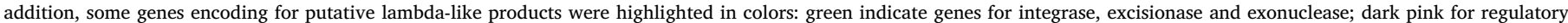

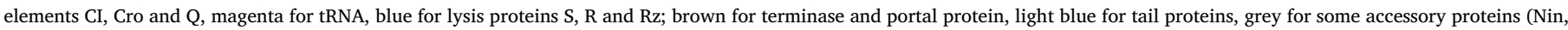

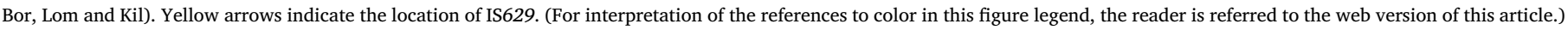

bacteriophage genomes provide valuable information about common and diverse characteristics among Stx phages and identification of possible factors that affect bacterial fitness and/or virulence. The development of new technologies facilitates bacterial whole-genome

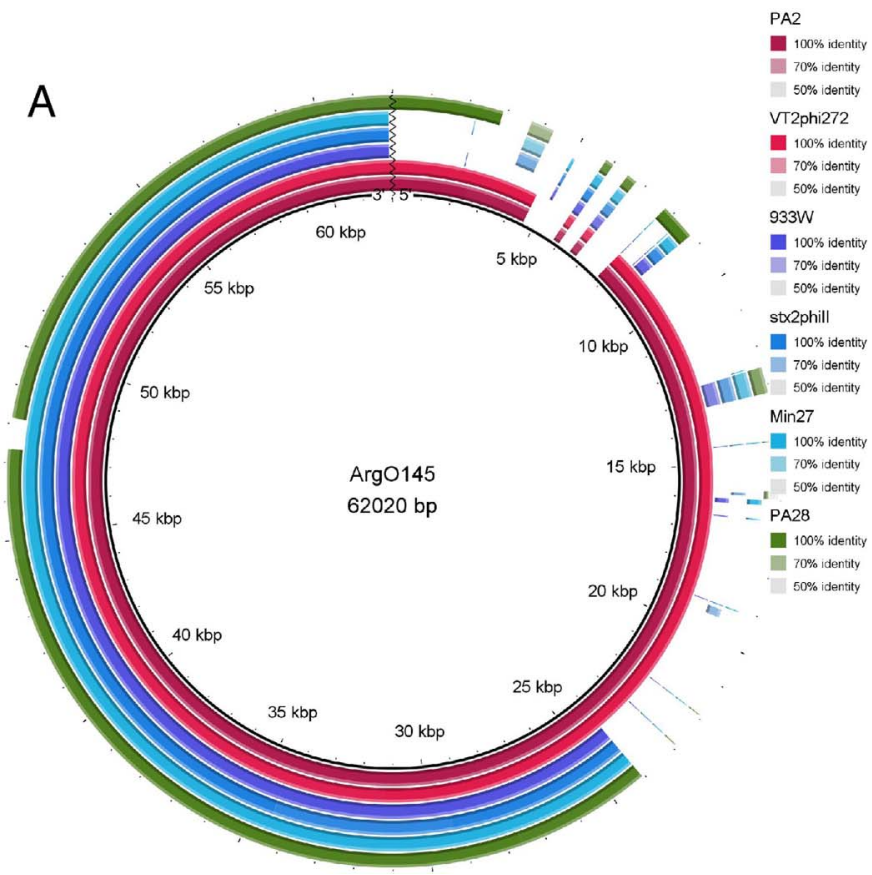

sequencing, including prophage sequences. However, the short read technology, and the common presence of other prophages (like in strain FB5) are factors that hinder the full de novo assembly of Stx phage genomes from bacterial sequences (Yin et al., 2015). In the present

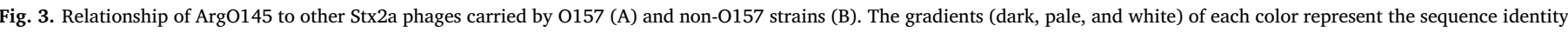
(from 100 to 0\%) between ArgO145 and the other Stx2a phages.

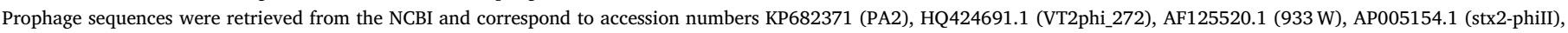
EU311208 (Min27), KP682381.1 (PA28), HE664024.1 (P13374), CP003289.1 (2011c-3493), JQ011318.1 (TL-2011c), CP006027.1 (RM13514). 
study, the complete genome of ArgO145 could be obtained in a single contig by combining data from two sequencing runs. Interestingly, Stx2a prophages of O157:H7 STEC strains isolated from humans in the U.S. (2006-2008), Japan (1995) and Canada (1995) showed a remarkable similarity to ArgO145 genome (Ogura et al., 2015; Yin et al., 2015; Zhang et al., 2007). In addition, the integration site of ArgO145, $\operatorname{argW}$, has been also reported as integration site for Stx 2 phages in O104:H4, O157:H7 (lineage I/II), O111:H and O145:H28 strains (Cooper et al., 2014; Laing et al., 2012).

Earlier studies on sequences of Stx phages described 5 gene clusters related to recombination, early regulation, replication, lysis, and head and tail structural gene regions (Miyamoto et al., 1999). However, it has been described that Stx phages are mosaic, with not all regions carrying genes conserved to the same degree. This is in line with the modular theory of evolution of lambdoid phages, which states that one region can be exchanged for another through recombination among phages infecting the same host (Brussow and Kutter, 2005). The results of comparative genomic analyses of ArgO145 with other Stx2a phages are in agreement with recent findings that highlight a divergence among Stx phage sequences (from 0157 strains) in recombination and early regulation regions with more conserved lysis and structural gene regions (Yin et al., 2015).

In particular, ArgO145 showed some differences with lambda and other Stx2a phages, like 933W, in genes associated to lysogeny control. Of the CI-CII-CIII circuitry generally present in lambdoid phages (Casjens and Hendrix, 2015), only the $c I$ gene was detected in ArgO145. Noticeably, both the cII gene, whose product is considered to be a central player in establishing lysogeny in lambda, and cIII, whose product controls stability of CII protein (Casjens and Hendrix, 2015), were not found. Similarly, other authors could not identify these two genes in Stx2a phages from an O104:H4 EAHEC strain of the 2011 German outbreak (Beutin et al., 2012, from an O111:H2 EAHEC strain (Grande et al., 2014), and two O157:H7 STEC strains (Yin et al., 2015). The exo-xis region, that was proposed to participate in the regulation of lysogenization and the promotion of phage induction, also differs from those described in $933 \mathrm{~W}$ and $\Phi 24 \mathrm{~b}$ prophages (Bloch et al., 2013; Licznerska et al., 2016). Interestingly, despite the particular characteristics of early regulatory genes in ArgO145, phage titers were similar for strains EDL933 and FB5, both in basal and induced conditions. It is worth to note that other factors encoded in the host, including the presence of other prophages, can also affect phage induction and toxin production (Yin et al., 2015).

In a recent study about Stx2a phages of STEC O157:H7 strains, Yin et al. (2015) identified three distinct clusters of phage sequence types (PSTs), that were designated PST1, PST2 and PST3, mostly differing in regions predicted to encode the phages' early regulatory and replication genes. These authors found that the PST2 cluster (which included PA2 and PA8 phages) was the most related to Stx2a phages from highly virulent non-O157 strains, including 0104:H4 and 0103:H2 strains. Interestingly, phylogenetic analysis showed that ArgO145 also clustered with this type (data not shown).

Among Stx phages of non-0157 strains those carried by the emerging O104:H4 EAHEC strains have been more extensively characterized (Ahmed et al., 2012; Beutin et al., 2012; Grande et al., 2014). A 900 bp sequence including a tail fiber gene was identified as uniquely associated with phages of EAHEC (Grande et al., 2014). In accordance, this sequence was not found in ArgO145.

Most Stx phages carry genes not required for core lambdoid phage replication and life cycle control, which have a hypothetical or unknown function (Smith et al., 2012). Moreover, recent studies showed that Stx phages may encode other factors that have an impact on their bacterial host (Su et al., 2010; Tozzoli et al., 2014; Veses-Garcia et al., 2015; Xu et al., 2012).

It is known that phages and phage resistance mechanisms have key roles in regulating bacterial populations (Labrie et al., 2010). It is suggested that methylases encoded by bacteriophages have functions similar to that of methylases found in bacterial cells (Murphy et al., 2013). In addition to protection from host restriction endonucleases, other effects of methylases have been proposed, such as maintenance of lysogeny, the packaging of phage DNA and controlling bacterial genes. Interestingly, the methyltransferase-endonuclease system detected in ArgO145 showed high similarity to that identified by Fang et al. (2012), which was shown to induce changes in the expression of many bacterial genes and pathways.

\section{Conclusions}

To our knowledge, this is the first report describing the genome of an inducible and infective Stx2a phage detected in a bovine STEC strain. Since Stx phages are highly diverse, it is remarkably that some Stx2a phages of strains isolated from patients in other countries showed high similarity to ArgO145. Noticeably, the highest sequence identity was found with phages from 0157:H7 strains. The characteristics of ArgO145 reinforce the conception that, considering phage characteristics, cattle can carry STEC strains potentially pathogenic for humans.

\section{Acknowledgments}

Authors thank E.G. Raangs and M.R. Ortiz for their technical assistance. This work was partly supported by the Interreg IVa-funded projects EurSafety Health-net (III-1-02=73) and SafeGuard (III-2$03=025$ ), and by grants from University Medical Center Groningen Healthy Ageing Pilots (279.419/RvB), National Scientific and Technical Research Council of Argentina-CONICET (PIP 0939 and Beca Externa para Jóvenes Investigadores), and Fondo para la Investigación Científica y Tecnológica (FONCYT-PICT 2438).

\section{References}

Ahmad, A., Zurek, L., 2006. Evaluation of the anti-terminator Q933 gene as a marker for Escherichia coli O157:H7 with high Shiga toxin production. Curr. Microbiol. 53, 324-328.

Ahmed, S.A., Awosika, J., Baldwin, C., Bishop-Lilly, K.A., Biswas, B., Broomall, S., Chain, P.S., Chertkov, O., Chokoshvili, O., Coyne, S., Davenport, K., Detter, J.C., Dorman, W., Erkkila, T.H., Folster, J.P., Frey, K.G., George, M., Gleasner, C., Henry, M., Hill, K.K., Hubbard, K., Insalaco, J., Johnson, S., Kitzmiller, A., Krepps, M., Lo, C.C., Luu, T., McNew, L.A., Minogue, T., Munk, C.A., Osborne, B., Patel, M., Reitenga, K.G., Rosenzweig, C.N., Shea, A., Shen, X., Strockbine, N., Tarr, C., Teshima, H., van Gieson, E., Verratti, K., Wolcott, M., Xie, G., Sozhamannan, S., Gibbons, H.S., 2012 Genomic comparison of Escherichia coli O104:H4 isolates from 2009 and 2011 reveals plasmid, and prophage heterogeneity, including Shiga toxin encoding phage Stx2. PLoS One 7, e48228.

Arndt, D., Grant, J.R., Marcu, A., Sajed, T., Pon, A., Liang, Y., Wishart, D.S., 2016. PHASTER: a better, faster version of the PHAST phage search tool. Nucleic Acids Res. 44, W16-21.

Beutin, L., Hammerl, J.A., Strauch, E., Reetz, J., Dieckmann, R., Kelner-Burgos, Y., Martin, A., Miko, A., Strockbine, N.A., Lindstedt, B.A., Horn, D., Monse, H., Huettel, B., Muller, I., Stuber, K., Reinhardt, R., 2012. Spread of a distinct Stx2-encoding phage prototype among Escherichia coli O104:H4 strains from outbreaks in Germany, Norway, and Georgia. J. Virol. 86, 10444-10455.

Beutin, L., Hammerl, J.A., Reetz, J., Strauch, E., 2013. Shiga toxin-producing Escherichia coli strains from cattle as a source of the Stx2a bacteriophages present in enteroaggregative Escherichia coli 0104:H4 strains. Int. J. Med. Microbiol. 303, 595-602.

Bloch, S., Nejman-Faleńczyk, B., Łoś, J.M., Barańska, S., Łepek, K., Felczykowska, A., Łoś, M., Węgrzyn, G., Węgrzyn, A., 2013. Genes from the exo-xis region of $\lambda$ and Shiga toxin-converting bacteriophages influence lysogenization and prophage induction. Arch. Microbiol. 195, 693-703.

Brussow, H., Kutter, E., 2005. Genomics and evolution of tailed phages. In: Kutter, E. Sulakvelidze, A. (Eds.), Bacteriophages: Biology and Applications, pp. 91-128 (Washington DC).

Casjens, S.R., Hendrix, R.W., 2015. Bacteriophage lambda: early pioneer and still relevant. Virology 479-480, 310-330.

Chui, L., Li, V., Fach, P., Delannoy, S., Malejczyk, K., Patterson-Fortin, L., Poon, A., King, R., Simmonds, K., Scott, A.N., Lee, M.C., 2015. Molecular profiling of Escherichia coli O157:H7 and non-O157 strains isolated from humans and cattle in Alberta, Canada. J. Clin. Microbiol. 53, 986-990.

Cooper, K.K., Mandrell, R.E., Louie, J.W., Korlach, J., Clark, T.A., Parker, C.T., Huynh, S., Chain, P.S., Ahmed, S., Carter, M.Q., 2014. Comparative genomics of enterohemorrhagic Escherichia coli O145:H28 demonstrates a common evolutionary lineage with Escherichia coli 0157:H7. BMC Genomics 15, 17. 
De Schrijver, K., Buvens, G., Possé, B., Van den Branden, D., Oosterlynck, O., De Zutter, L., Eilers, K., Piérard, D., Dierick, K., Van Damme-Lombaerts, R., 2008. Outbreak of verocytotoxin-producing $E$. coli $\mathrm{O} 145$ and $\mathrm{O} 26$ infections associated with the consumption of ice cream produced at a farm, Belgium, 2007. Euro Surveill. 13, 61-64.

EFSA Panel, B.H.B., 2013. Scientific opinion on VTEC-seropathotype and scientific criteria regarding pathogenicity assessment. EFSA J. 11, 3138.

Fang, G., Munera, D., Friedman, D.I., Mandlik, A., Chao, M.C., Banerjee, O., Feng, Z., Losic, B., Mahajan, M.C., Jabado, O.J., Deikus, G., Clark, T.A., Luong, K., Murray, I.A., Davis, B.M., Keren-Paz, A., Chess, A., Roberts, R.J., Korlach, J., Turner, S.W., Kumar, V., Waldor, M.K., Schadt, E.E., 2012. Genome-wide mapping of methylated adenine residues in pathogenic Escherichia coli using single-molecule real-time sequencing. Nat. Biotechnol. 30, 1232-1239.

Feng, P.C.H., Delannoy, S., Lacher, D.W., dos Santos, L.F., Beutin, L., Fach, P., Rivas, M., Hartland, E.L., Paton, A.W., Guth, B.E.C., 2014. Genetic diversity and virulence potential of Shiga toxin-producing Escherichia coli O113:H21 strains isolated from clinical, environmental, and food sources. Appl. Environ. Microbiol. 80, 4757-4763.

Feng, P.C., Delannoy, S., Lacher, D.W., Bosilevac, J.M., Fach, P., Beutin, L., 2017. Characterization of Shiga toxin-producing Escherichia coli strains of O91 serogroup isolated from food and environmental samples. Appl. Environ. Microbiol. 42, 1099-1108. http://dx.doi.org/10.1128/AEM.01231-17.

Friedrich, A.W., Bielaszewska, M., Zhang, W.L., Pulz, M., Kuczius, T., Ammon, A., Karch, H., 2002. Escherichia coli harboring Shiga toxin 2 gene variants: frequency and association with clinical symptoms. J. Infect. Dis. 185, 74-84.

FSIS, U., 2011. Draft Risk Profile for Pathogenic Non-0157 Shiga-toxin Producing Escherichia coli (Non-O157 STEC).

Gould, L.H., Mody, R.K., Ong, K.L., Clogher, P., Cronquist, A.B., Garman, K.N., Lathrop, S., Medus, C., Spina, N.L., Webb, T.H., White, P.L., Wymore, K., Gierke, R.E., Mahon, B.E., Griffin, P.M., Emerging Infections Program Foodnet Working, G, 2013. Increased recognition of non-O157 Shiga toxin-producing Escherichia coli infections in the United States during 2000-2010: epidemiologic features and comparison with $E$. coli $\mathrm{O} 157$ infections. Foodborne Pathog. Dis. 10, 453-460.

Grande, L., Michelacci, V., Tozzoli, R., Ranieri, P., Maugliani, A., Caprioli, A., Morabito, S., 2014. Whole genome sequence comparison of vtx2-converting phages from enteroaggregative haemorrhagic Escherichia coli strains. BMC Genomics 15, 574.

Gyles, C., 2007. Shiga toxin-producing Escherichia coli: an overview. J. Anim. Sci. 85, E45-E62.

Hatfull, G.F., Hendrix, R.W., 2011. Bacteriophages and their genomes. Curr. Opin. Virol. 1, 298-303.

Johansen, B.K., Wasteson, Y., Granum, P.E., Brynestad, S., 2001. Mosaic structure of Shiga-toxin-2-encoding phages isolated from Escherichia coli O157: H7 indicates frequent gene exchange between lambdoid phage genomes. Microbiology 147, 1929-1936.

Karmali, M.A., Petric, M., Lim, C., Fleming, P.C., Arbus, G.S., Lior, H., 1985. The association between idiopathic hemolytic uremic syndrome and infection by verotoxinproducing Escherichia coli. J. Infect. Dis. 151, 775-782.

Kaspar, C., Doyle, M.E., Archer, J., 2010. White paper on non-O157:H7 Shiga toxinproducing $E$. coli from meat and non-meat sources. In: FRI Food Saf Rev.

Kluytmans-Van Den Bergh, M.F., Rossen, J.W., Bruijning-Verhagen, P.C., Bonten, M.J., Friedrich, A.W., Vandenbroucke-Grauls, C.M., Willems, R.J., Kluytmans, J.A., 2016. Whole-genome multilocus sequence typing of extended-spectrum-beta-lactamaseproducing Enterobacteriaceae. J. Clin. Microbiol. 54, 2919-2927.

Krüger, A., Lucchesi, P.M., Parma, A.E., 2011. Verotoxins in bovine and meat verotoxinproducing Escherichia coli isolates: type, number of variants, and relationship to cy totoxicity. Appl. Environ. Microbiol. 77, 73-79.

Krüger, A., Lucchesi, P.M., Sanso, A.M., Etcheverría, A.I., Bustamante, A.V., Burgán, J., Fernández, L., Fernández, D., Leotta, G., Friedrich, A.W., 2015. Genetic characterization of Shiga toxin-producing Escherichia coli O26: H11 strains isolated from animal, food, and clinical samples. Front. Cell. Infect. Microbiol. 5.

Kutter, E., Sulakvelidze, A., 2004. Bacteriophages: Biology and Applications. CRC Press.

Labrie, S.J., Samson, J.E., Moineau, S., 2010. Bacteriophage resistance mechanisms. Nat. Rev. Microbiol. 8, 317-327.

Laing, C.R., Zhang, Y., Gilmour, M.W., Allen, V., Johnson, R., Thomas, J.E., Gannon, V.P.J., 2012. A comparison of Shiga-toxin 2 bacteriophage from classical Enterohemorrhagic Escherichia coli serotypes and the German E. coli O104:H4 outbreak strain. PLoS One 7, e37362.

Lejeune, J.T., Abedon, S.T., Takemura, K., Christie, N.P., Sreevatsan, S., 2004. Human Escherichia coli O157:H7 genetic marker in isolates of bovine origin. Emerg. Infect. Dis. 10.

Lenzi, L.J., Lucchesi, P.M., Medico, L., Burgán, J., Krüger, A., 2016. Effect of the food additives sodium citrate and disodium phosphate on Shiga toxin-producing Escherichia coli and production of stx-phages and Shiga toxin. Front. Microbiol. 7.

Licznerska, K., Dydecka, A., Bloch, S., Topka, G., Nejman-Faleńczyk, B., Wegrzyn, A., Węgrzyn, G., 2016. The role of the exo-xis region in oxidative stress-mediated induction of Shiga toxin-converting prophages. Oxidative Med. Cell. Longev. 2016, 8453135 .

Miyamoto, H., Nakai, W., Yajima, N., Fujibayashi, A., Higuchi, T., Sato, K., Matsushiro, A., 1999. Sequence analysis of Stx2-converting phage VT2-Sa shows a great divergence in early regulation and replication regions. DNA Res. 6, 235-240.

Murphy, J., Mahony, J., Ainsworth, S., Nauta, A., van Sinderen, D., 2013. Bacteriophage orphan DNA methyltransferases: insights from their bacterial origin, function, and occurrence. Appl. Environ. Microbiol. 79, 7547-7555.

Nübling, S., Eisele, T., Stöber, H., Funk, J., Polzin, S., Fischer, L., Schmidt, H., 2014
Bacteriophage 933W encodes a functional esterase downstream of the Shiga toxin 2a operon. Int. J. Med. Microbiol. 304, 269-274.

Ogura, Y., Mondal, S.I., Islam, M.R., Mako, T., Arisawa, K., Katsura, K., Ooka, T., Gotoh, Y., Murase, K., Ohnishi, M., Hayashi, T., 2015. The Shiga toxin 2 production level in enterohemorrhagic Escherichia coli O157:H7 is correlated with the subtypes of toxinencoding phage. Sci. Rep. 5, 16663.

Padola, N.L., Sanz, M.E., Lucchesi, P.M., Blanco, J.E., Blanco, J., Blanco, M., Etcheverría, A.I., Arroyo, G.H., Parma, A.E., 2002. First isolation of the enterohaemorrhagic Escherichia coli 0145:H- from cattle in feedlot in Argentina. BMC Microbiol. 2, 6.

Persad, A.K., LeJeune, J.T., 2014. Animal reservoirs of Shiga toxin-producing Escherichia coli. Microbiol. Spectr. 2.

Persson, S., Olsen, K.E.P., Ethelberg, S., Scheutz, F., 2007. Subtyping method for Escherichia coli Shiga toxin (Verocytotoxin) 2 variants and correlations to clinical manifestations. J. Clin. Microbiol. 45, 2020-2024.

Riley, L.W., Remis, R.S., Helgerson, S.D., McGee, H.B., Wells, J.G., Davis, B.R., Hebert, R.J., Olcott, E.S., Johnson, L.M., Hargrett, N.T., 1983. Hemorrhagic colitis associated with a rare Escherichia coli serotype. N. Engl. J. Med. 308, 681-685.

Rivas, M., Padola, N.L., Lucchesi, P.M., Masana, M., 2010. Diarrheagenic Escherichia coli in Argentina. In: Torres, A.G. (Ed.), Pathogenic Escherichia coli in Latin America. Bentham. Science Publishers, pp. 142-161.

de Sablet, T., Bertin, Y., Vareille, M., Girardeau, J.-P., Garrivier, A., Gobert, A.P., Martin, C., 2008. Differential expression of stx2 variants in Shiga toxin-producing Escherichia coli belonging to seropathotypes A and C. Microbiology 154, 176-186.

Smith, D.L., James, C.E., Sergeant, M.J., Yaxian, Y., Saunders, J.R., McCarthy, A.J., Allison, H.E., 2007. Short-tailed Stx phages exploit the conserved YaeT protein to disseminate Shiga toxin genes among enterobacteria. J. Bacteriol. 189.

Smith, D.L., Rooks, D.J., Fogg, P.C.M., Darby, A.C., Thomson, N.R., McCarthy, A.J., Allison, H.E., 2012. Comparative genomics of Shiga toxin encoding bacteriophages. BMC Genomics 13, 311.

Steyert, S.R., Sahl, J.W., Fraser, C.M., Teel, L.D., Scheutz, F., Rasko, D.A., 2012 Comparative genomics and stx phage characterization of LEE-negative Shiga toxinproducing Escherichia coli. Front. Cell. Infect. Microbiol. 2, 133.

Su, L.K., Lu, C.P., Wang, Y., Cao, D.M., Sun, J.H., Yan, Y.X., 2010. Lysogenic infection of a Shiga toxin 2-converting bacteriophage changes host gene expression, enhances host acid resistance and motility. Mol. Biol. 44, 54-66.

Sullivan, M.J., Petty, N.K., Beatson, S.A., 2011. Easyfig: a genome comparison visualizer. Bioinformatics 27, 1009-1010.

Suttle, C.A., 2016. Environmental microbiology: viral diversity on the global stage. Nat. Microbiol. 1, 16205.

Taylor, E.V., Nguyen, T.A., Machesky, K.D., Koch, E., Sotir, M.J., Bohm, S.R., Folster, J.P., Bokanyi, R., Kupper, A., Bidol, S.A., Emanuel, A., Arends, K.D., Johnson, S.A., Dunn, J., Stroika, S., Patel, M.K., Williams, I., 2013. Multistate outbreak of Escherichia coli O145 infections associated with romaine lettuce consumption, 2010. J. Food Prot. 76, 939-944.

Tozzoli, R., Grande, L., Michelacci, V., Fioravanti, R., Gally, D., Xu, X., La Ragione, R., Anjum, M., Wu, G., Caprioli, A., Morabito, S., 2014. Identification and characterization of a peculiar $v t \times 2$-converting phage frequently present in verocytotoxin-producing Escherichia coli O157 isolated from human infections. Infect. Immun. 82, 3023-3032.

Tyler, J.S., Beeri, K., Reynolds, J.L., Alteri, C.J., Skinner, K.G., Friedman, J.H., Eaton, K.A., Friedman, D.I., 2013. Prophage induction is enhanced and required for renal disease and lethality in an EHEC mouse model. PLoS Pathog. 9, e1003236.

Veses-Garcia, M., Liu, X., Rigden, D.J., Kenny, J.G., McCarthy, A.J., Allison, H.E., 2015. Transcriptomic analysis of Shiga-toxigenic bacteriophage carriage reveals a profound regulatory effect on acid resistance in Escherichia coli. Appl. Environ. Microbiol. 81, 8118-8125.

Wagner, P.L., Waldor, M.K., 2002. Bacteriophage control of bacterial virulence. Infect. Immun. 70, 3985-3993.

Wagner, P.L., Neely, M.N., Zhang, X., Acheson, D.W., Waldor, M.K., Friedman, D.I., 2001. Role for a phage promoter in Shiga toxin 2 expression from a pathogenic Escherichia coli strain. J. Bacteriol. 183, 2081-2085.

Wahl, E., Vold, L., Lindstedt, B.A., Bruheim, T., Afset, J.E., 2011. Investigation of an Escherichia coli $\mathrm{O} 145$ outbreak in a child day-care centre-extensive sampling and characterization of eae-and stx1-positive E. coli yields epidemiological and socioeconomic insight. BMC Infect. Dis. 11, 238.

Waldor, M.K., Friedman, D.I., 2005. Phage regulatory circuits and virulence gene expression. Curr. Opin. Microbiol. 8, 459-465.

Xu, X., McAteer, S.P., Tree, J.J., Shaw, D.J., Wolfson, E.B.K., Beatson, S.A., Roe, A.J., Allison, L.J., Chase-Topping, M.E., Mahajan, A., Tozzoli, R., Woolhouse, M.E.J., Morabito, S., Gally, D.L., 2012. Lysogeny with Shiga toxin 2-encoding bacteriophages represses type III secretion in Enterohemorrhagic Escherichia coli. PLoS Pathog. 8, e1002672.

Yin, S., Rusconi, B., Sanjar, F., Goswami, K., Xiaoli, L., Eppinger, M., Dudley, E.G., 2015. Escherichia coli O157:H7 strains harbor at least three distinct sequence types of Shiga toxin 2a-converting phages. BMC Genomics 16, 733.

Zhang, Y., Laing, C., Steele, M., Ziebell, K., Johnson, R., Benson, A.K., Taboada, E., Gannon, V.P., 2007. Genome evolution in major Escherichia coli O157:H7 lineages. BMC Genomics 8, 1-16.

Zotta, C.M., Chinen, I., Lavayén, S., Carbonari, C., Monzani, V., Morvay, L., Rivas, M., 2014. Diversidad genética de cepas de Escherichia coli O145: NM/H27 aisladas en la provincia de Buenos Aires. Acta Bioquím. Clín. Latinoam. 48, 81-85. 